\title{
Burden of VSD associated aortic valve cusp prolapse with aortic regurgitation and the impact of early surgery on clinical outcomes in South Asia
}

\author{
Sahrai Saeed ${ }^{1}$, Yaso Emmanuel ${ }^{2}$
}

doi: https://doi.org/10.12669/pjms.37.5.4845

\section{How to cite this:}

Saeed S, Emmanuel Y. Burden of VSD associated aortic valve cusp prolapse with aortic regurgitation and the impact of early surgery on clinical outcomes in South Asia. Pak J Med Sci. 2021;37(5):1259-1261. doi: https://doi.org/10.12669/pjms.37.5.4845

This is an Open Access article distributed under the terms of the Creative Commons Attribution License (http://creativecommons.org/licenses/by/3.0), which permits unrestricted use, distribution, and reproduction in any medium, provided the original work is properly cited.

Congenital heart disease (CHD) is defined as a structural defect in the heart or the great vessels present at birth. It includes a range of conditions, ventricular septal defect (VSD) being one of them (Figure 1), which is mostly diagnosed and when indicated, is treated in childhood., ${ }^{1,2}$ Undetected VSDs are associated with higher mortality and morbidity. VSDs may be either simple/isolated or complex and co-present with other cardiac lesions. ${ }^{3}$ VSDs can be divided into subgroups according to the location in the right ventricle: membranous (approximately $80 \%$ of VSDs - these can extend into the outlet, trabecular or inlet portions of the septum), muscular/trabecular (15-20\%) and outlet sub-arterial defects. ${ }^{1,2}$ VSDs that involve the outlet septum may be associated with progressive aortic regurgitation (AR) due to prolapse of the right aortic cusp and aneurysm of the sinus of Valsalva. ${ }^{4}$ It has been shown that up to $40 \%$ patients with VSDassociated right aortic cusp prolapse can develop AR. ${ }^{5}$ A simple VSD may close spontaneously and in these patients survival rates are very high. ${ }^{3}$

1. Sahrai Saeed,

Department of Heart Disease,

Haukeland University Hospital,

Bergen, Norway.

2. Yaso Emmanuel,

Cardiovascular Department,

Guy's and St Thomas' Hospital,

London, UK.

Correspondence:

Sahrai Saeed MD, PhD, FESC,

Department of Heart Disease,

Haukeland University Hospital,

Bergen, Norway.

E-mail: sahrai.saeed@helse-bergen.no
VSD closure is indicated when there is associated haemodynamically significant left ventricular volume overload secondary to the shunt and in the absence of significant pulmonary hypertension. ${ }^{1,2}$ Progressive aortic cusp prolapse and regurgitation is a class IIa indication for VSD closure ${ }^{1,2}$ in order to try to preserve the aortic valve.

Patients with small defects that are not deemed to require closure in childhood should remain under follow-up as there can be sequelae, including progressive $A R$, progressive left ventricular dilatation, pulmonary hypertension, progressive muscle bundle formation in the right ventricular outflow tract leading to the development of a double-chambered right ventricle, and infective endocarditis may also occur as a result of jet lesions in the right ventricle ${ }^{1,2}$ Karonis et al. reported on the adult outcomes in a UK population with small VSDs that did not require closure in childhood who were under follow-up at a specialist centre. ${ }^{6}$ They identified 231 patients and $83 \%$ had defects involving either the perimembranous septum or sub-arterial septum, the remaining $17 \%$ had muscular defects. Overall long-term outcomes were good with no mortality and $97 \%$ were asymptomatic. However, 26 patients $(11 \%)$ did require surgery for associated complications mostly for the development of a double chambered right ventricle $(n=17,65 \%)$ and infective endocarditis $(n=6,23 \%)$. Only two patients required surgery for progressive left to right shunting. AR was identified in 26 patients, (11\%) and in these patients this was graded as mild in 21 and more than mild in the remaining five, but only one patient required surgery for progressive AR. 
VSD with aortic cusp prolapse and subsequent AR is rare (approximately 5\%) in North America and Western Europe, but is more common in the Asian populations. ${ }^{4,5,7,8}$ Kumari et al. reviewed a South Asian population with VSDs over a two year period and identified AR in $23 \%$ of patients. ${ }^{9}$ In this study, $17.9 \%$ of defects closed spontaneously, $51.6 \%$ of patients underwent surgery and in $30.5 \%$ of patients there was no indication for surgery. The prevalence of AR significantly reduced following surgery, however, the incidence of later AR in the un-operated patients is not known in this study.

Over the past two decades, the diagnostic imaging modalities and therapeutic approaches have improved, leading to better outcomes in CHD patients. In a prospective study of 7038 patients $<16$ years undergoing surgical treatment for CHD in Norway, cumulative survival until 16 years of age with complex CHD was $62.4 \%$ between 1971 to 1989 and $86.9 \%$ between 1990 to $2011(\mathrm{p}<0.0001)$. This trend was also particularly evident for patients with atrioventricular septal defects. ${ }^{10}$ However, the prevalence of VSDassociated aortic cusp prolapse and associated $\mathrm{AR}$, and burden of residual AR following VSD surgery were not reported. Probably, this reflects the relatively low prevalence of VSD-associated $\mathrm{AR}$ in Scandinavian populations compared with south Asians. Internationally, given the overall continued improvement in surgical outcomes, some argue for earlier intervention on VSDs with aortic valve prolapse in order to prevent AR.
In a recent edition of the Pakistan Journal of Medical Science (Pak J Med Sci), Waqar et al. presented some interesting results for surgical outcomes of repair of VSD-associated aortic valve prolapse. ${ }^{4}$ The authors studied 72 patients with VSD-associated aortic valve prolapse operated in Punjab Institute of Cardiology between 2016 and 2020 (18 patients per year). In 55 patients, AR was either absent $(n=15$, group I) or mild $(n=40$, group II). In 17 patients VSD was either associated with moderate AR $(n=10$, group III) or severe AR $(n=7$, group IV). VSD was closed in all patients, but AR was treated surgically in 17 patients with moderate or severe AR (group III-IV). After a mean followup of 3 to 3.5 years, the outcome were excellent with no late mortalities: in majority of patients, residual AR was either absent or not significant (trace or mild), while only in two patients AR was considered clinically significant and scheduled for redo operations. The authors in this study focused on patients with aortic valve involvement and the outcomes in Groups I and II appeared good on the face of it in terms of the lack of AR at followup. However it is not clear what the indication for surgery was in the first place in these groups. Both of these groups underwent VSD closure only and did not require valve repair. If closure was indicated on the basis of a haemodynamically significant shunt, then this would not be deemed 'early' closure. Previous work, ${ }^{11}$ also published in the Pakistan Journal of Medical Science by the same author group but from a different tertiary heart center, reported on patients with sub-arterial

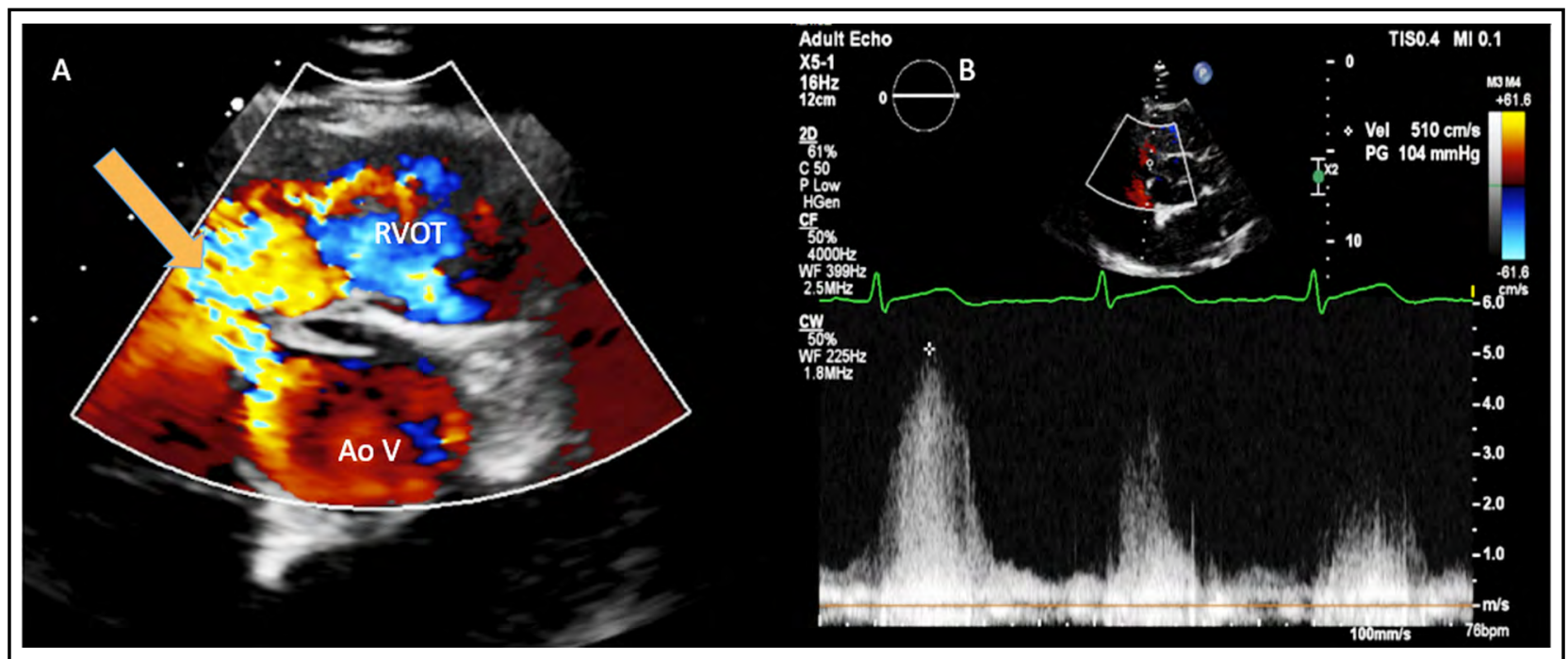

Fig.1. Panel A: Parasternal short axis view with colour Doppler showing the left to right jet through the VSD (red arrow). Panel B: Continuous wave Doppler trace on parasternal short axis view through the jet indicating high velocity left to right flow at $5.0 \mathrm{~m} / \mathrm{s}$ consistent with a restrictive VSD. VSD, ventricular septal defect. 
VSD undergoing surgery. As with the most recent work, the study population was similarly classified according to the degree of aortic valve involvement. Similar results were reported over the short follow-up period (1.5-2.8 years). Again the indication for surgery in patients with no significant AR was not clear. Overall, the studies of Waqar et al.4,11 deserve appreciation and show that mid-term outcomes are excellent in CHD patients. This reflects their surgical skills and experiences at a "high-volume" tertiary center. However, it is important to note that in both studies, the indication for surgery in patients without significant or progressive AR was not clear. Without knowing more about the indication for surgery, it is difficult to address the question of whether there is a role for early isolated VSD closure before progressive regurgitation develops in order to preserve the valve and avoid valve repair, if closure is not indicated on haemodynamic grounds.

From previous European studies it is known that in surgically treated VSD patients, AR can occur late in follow-up and is a major subject of concern. Given the relatively short follow-up time in Waqar et al.'s most recent cohort, it is probably too early to evaluate occurrence of late AR. For comparison, results from a study in the Netherlands showed that the occurrence of AR after VSD surgery was worrying. Although overall survival was good ( $86 \%$ at 40 years), the percentage of patients with mild or moderate AR increased from $10 \%$ to $21 \%$ over the last 20 years of follow-up. ${ }^{12}$

The data from Karonis et al. ${ }^{6}$ suggest that with small defects, the incidence of late aortic valve involvement is low. Additional longer follow-up studies in different populations to evaluate the late development of $\mathrm{AR}$ and other complications that require surgical intervention in patients in whom closure was not indicated in childhood will be helpful. The results reported by Waqar et al.,11 appear promising, however, longer follow-up of patients with aortic valve involvement but only undergoing isolated VSD closure is required both to assess for late AR and to identify whether the incidence of other associated complications or need for surgical re-intervention is less than in patients with small defects who are un-operated. The data on longer term outcomes of both these groups are needed to determine the role of early surgical intervention to preserve the aortic valve.

Funding: This work was not funded.
The opinion expressed in the present expert commentary is the view of the authors and does not necessarily reflect the view of the institutions the authors belong to.

\section{REFERENCES}

1. Stout KK, Daniels CJ, Aboulhosn JA, Bozkurt B, Broberg CS, Colman JM, et al. 2018 AHA/ACC Guideline for the Management of Adults With Congenital Heart Disease: A Report of the American College of Cardiology/ American Heart Association Task Force on Clinical Practice Guidelines. Circulation. 2019;139(14):e698-e800.

2. Baumgartner H, De Backer J, Babu-Narayan SV, Budts W, Chessa M, Diller GP, et al. ESC Scientific Document Group. 2020 ESC Guidelines for the management of adult congenital heart disease. Eur Heart J. 2021;42(6):563-645.

3. van der Bom T, Bouma BJ, Meijboom FJ, Zwinderman $\mathrm{AH}$, Mulder BJ. The prevalence of adult congenital heart disease, results from a systematic review and evidence based calculation. Am Heart J. 2012;164(4):568-575.

4. Waqar T, Rizvi MFA, Nasir JA, Khan K. Surgical outcome of repair of aortic valve prolapse and regurgitation associated with ventricular septal defect. Pak J Med Sci. 2021;37(3).

5. Iwashima S, Uchiyama $\mathrm{H}$, Ishikawa $\mathrm{T}$, Takigiku $\mathrm{K}$, Takahashi K, Toyono M, et al. Measurement of Aortic Valve Coaptation and Effective Height Using Echocardiography in Patients with Ventricular Septal Defects and Aortic Valve Prolapse. Pediatr Cardiol. 2017; 38(3):608-616.

6. Karonis T, Scognamiglio G, Babu-Narayan S, Uebing, Diller $\mathrm{G}$, et al. Clinical course and potential complications of small ventricular septal defects in adulthood: late development of left ventricular dysfunction justifies lifelong care. Int J Cardiol. 2016; 208:102-6.

7. Soto B, Becker AE, Moulaert AJ, Lie JT, Anderson RH. Classification of ventricular septal defects. Br Heart J. 1980; 43:332.

8. Ando M, Takao A. Pathological anatomy of ventricular septal defect associated with aortic valve prolapse and regurgitation. Heart Vessels. 1986; 2:117.

9. Kumari V, Shaikh AS, Zakai SB, Kumar N, Bangash SK, Patel N. Incidence of Aortic Regurgitation in Association with Type of Ventricular Septal Defects and its Immediate and Intermediate Outcome after Surgical Closure. Cureus. 2019 Jul 8;11(7):e5102.

10. Erikssen G, Liestøl K, Seem E, Birkeland S, Saatvedt KJ, Hoel TN, et al. Achievements in congenital heart defect surgery: a prospective, 40-year study of 7038 patients. Circulation. 2015;131(4):337-346.

11. Waqar T, Rizvi MFA, Baig AR. Doubly committed Subarterial Ventricular Septal defect repair: An experience of 51 cases. Pak J Med Sci. 2017; 33(5):1112-1116.

12. Menting ME, Cuypers JA, Opić P, Utens EM, Witsenburg $\mathrm{M}$, van den Bosch AE et al. The unnatural history of the ventricular septal defect: Outcome up to 40 years after surgical closure. J Am Coll Cardiol. 2015; 65:1941-1951.

\section{Authors Contribution:}

SS wrote the first draft of the article, which was subsequently revised for important scientific content by YE. Both authors approved the final submission.

\section{Conflict of Interest: None.}

